\title{
Mapping and monitoring ground instabilities with Sentinel-1 data: the experience of Sernageomin
}

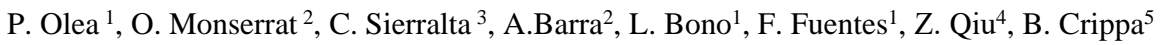 \\ ${ }^{1}$ Unidad de teledetección, Departamento de Geomática. Servicio Nacional de Geología y Minería (Sernageomin), Santiago de Chile, \\ RM, Chile.paula.olea@sernageomin.cl \\ ${ }^{2}$ Centre Tecnològic de Telecomunicacions de Catalaunya, Av. Carl Friedrich Gauss, 4, Castelldefels, Spain, \\ ${ }^{3}$ Superintendencia del Medio Ambiente. Santiago de Chile, RM, Chile \\ ${ }^{4}$ School of Geomatics and Marine Information, Jiangsu Ocean University, Av. Cangwu 59, Lianyungang, China, qiuzhiwei- \\ 2008@163.com \\ ${ }^{5}$ Department of Earth Sciences, Section of Geophysics, University of Milan, Via Cicognara, 7, I-20129, Milan, Italy,
}

KEY WORDS: Active geohazards, SAR interferometry, Sentinel-1, geohazard prevention

\begin{abstract}
:
The application of Satellite Differential SAR interferometry (DInSAR) has become a reliable solution as a tool for mapping and monitoring geohazards. Few years ago, the main applications of these techniques were devoted to science. However, nowadays, the easy access to SAR imagery and the maturity of the techniques to exploit these type of data has widened the user's spectrum from only scientists to professional and decision makers. The advent of Sentinel-1 satellites has significantly contributed to this achievement. In particular, in the field of geohazard risk management, Sentinel-1 has solved one of the main constraining factors that hindered the operational use of interferometric techniques in the past: the lack of systematic acquisition plans. In this context, Sentinel-1 assures worldwide coverage with short temporal baselines (6 to 24 days). This has supposed a definitive step towards the implementation of DInSAR based techniques to support decision makers against geohazards. In this work, we show the first experiences of the remote sensing unit of the Geological and Mining Survey of Chile (Sernageomin) with Sentinel-1 data. Three different case studies in different areas of the Chilean territory are presented. The examples illustrate how DInSAR based techniques can provide different levels of information about geohazard activity in different environments.
\end{abstract}

\section{INTRODUCTION}

At the beginning of this century, the use of Differential SAR interferometry was almost limited to scientific applications and still considered a non conventional tool for mapping and monitoring ground displacements (Kimura and Yamaguchi 2000; Catani et al. 2005). However, the development of advanced methods to exploit stacks of images providing objective measurements of displacements supposed an important step forward to consolidate DInSAR as a reliable geodetic data (Ferretti et al. 2001, Berardino et al. 2002). These methods, here in advance referred as Advanced-DInSAR (A-DInSAR) methods, are based on estimation tools, statistical analysis, models and image processing (Constantini et al. 2002, Lanari et al. 2005, Lombardini et al. 2005 and Biescas et al. 2007). Its development allowed the use of DInSAR interferometry in a wide range of applications like volcanoes (Hooper et al. 2009, Gonzalez et al. 2015), landslides (Herrera et al. 2009, Bovenga et al 2012), ground subsidences (Racoules et al. 2009, Osmanoğlu et al. 2011) or civil engineering (Monserrat et al. 2011, Tomas et al. 2013).

The Geological and Mining Survey of Chile (Sernageomin) is a public body responsible for generating, maintaining and disseminating information about basic geology, geological resources and geological hazards along the national territory. The main goals of Sernageomin are to contribute to the well-being of the community, to give support on the regulation and supervision of the compliance with mining regulations on security, property and closure plans and to contribute to the development of national mining. Sernageomin has a department that deals with remote sensing techniques applied to give support to these goals. Among others, DInSAR technique is one of them capabilities and since last years are part of the used tools to map and monitor geohazards.
In this work we show how these techniques combined with the performances provided by the Satellite SAR Sentinel-1 constellation (Torres et al. 2012) are used at Sernageomin for two different purposes: (i) mapping active geohazards that is useful to collect information on wide areas about the activity of known geohazards and to detect new active ones and (ii) to monitor known phenomena. The examples show three different areas of the Chilean territory: the metropolitan area of Valparaíso, the city of Santiago and the Copiapó river basin in the Atacama Region.

The paper follows with three more sections. In Section 2 are described the results of Valparaíso, Santiago and Copiapó whose main goal was related to map active areas. In section 3 is shown the result obtained on a tailing dam as an example of monitoring. Finally, it closes with a brief discussion and conclusions.

\section{SENTINEL-1 A-DINSAR FOR GEOHAZARD ACTIVITY ASSESSMENT IN URBAN AREAS}

Sentinel-1 SAR satellites have supposed a step forward on the use of DInSAR techniques for geohazard mapping and monitoring (Barra et al. 2016). The acquisition policy, assuring a worldwide coverage each 6-24 days depending on the area and the free access to the images provide an excellent framework to systematically assess the geohazard activity at regional level (Raspini et al. 2018). Moreover, the provided resolution, approximately 4 meter in range direction by 14 meters in azimuth direction, is good enough for a wide number of applications (Raspini et al. 2018). These good performances allowed to design national plans in Europe to systematically map the ground movement at national level (Kalia et al. 2017, Bredal et al 2019) or at European level (EGS 2017). 
The appearance of Sentinel-1 and the corresponding operational applications have also made grow the need of post-processing tools to ease the interpretation and analysis of the DInSAR results to non-expert users (Barra et al. 2017, Bejar et al. 2018, Tomas et al. 2019).

In this section are shown two examples of urban monitoring application. The results have been obtained at the Sernageomin by using Sentinel-1 data and DInSAR tools developed by the Technological Centre of Catalunya and the University of Milan (Crosetto et al. 2011, Devanthery et al. 2014). The selected areas are the cities of Santiago and Valparaíso. The main goal of these type of analysis is to detect and map active geological processes in this areas.

\subsection{Dataset and used approach}

The processing of Valparaíso and Santiago has been performed by using the same dataset. Both cities are included in the same Sentinel-1 frame. The number of used images is 51 . The acquisition period ranges from $3^{\text {rd }}$ of March 2017 to $12^{\text {th }}$ of December 2018. The used approach provides, for a selected set of points, the displacement velocity represented in $\mathrm{mm} / \mathrm{yr}$. It is described in Biescas et al. 2007. The estimation method is the periodogram (Ferretti et al. 2000). It consists in finding the velocity that maximizes the temporal coherence (TC) in the following equation:

$$
T C(e)=\frac{1}{N} *\left|\sum_{I=1}^{N} e^{j\left(\Delta \varphi_{i}(e)-F_{i}(v(e), t e(e))\right)}\right|
$$

Where $\mathrm{N}$ is the number of interferograms used as input, $\Delta \varphi_{i}(e)$ is the i-th interferometric phase at point $e$ and $F_{i}(v(e), t e(e)$ is the modelled $\mathrm{i}$-th interferogram assuming a velocity $v$ and a height $t e$ of the point $e$ with respect the digital elevation model used during the interferogram calculation. In this work, the velocity map contains only those points with $T C$ higher than 0.7 .

\subsection{Obtained results}

Figure 1 shows an image obtained by averaging the 51 amplitude images over the area of Santiago (upper image) and Valparaíso (bottom image). These images are useful to identify key features and interpret the DInSAR results. They represent the average response of each target along the stack of images. The whiter colors are points with strong response (e.g. urban areas), the darker ones refer to surfaces with weak response (e.g. water bodies).

Figure 2 shows the obtained deformation velocity map in Santiago (up) and Valparaíso (down). The colors represent the different velocities. Values towards red means point that are going far with respect the satellite (subsidence in case of vertical displacements). The points with blue tones are moving towards the satellite. It can be seen that most of the areas are green, i.e. stable. The total number of measured points are around 1.6 million in Santiago and 525 thousand in Valparaíso. The overall estimated precision is $2.1 \mathrm{~mm} / \mathrm{yr}$.

These maps can be used to identify areas that are affected by displacement and to decide whether or not is useful to perform a more in depth analysis. As an example, Figure 3 focus in two examples of detected active areas. In Figure $3 \mathrm{~A}$ is shown an industrial area located in the north-west part of the Santiago city. The maximum observed velocity is $28 \mathrm{~mm} / \mathrm{yr}$.
In this case, the movement is interpreted as a subsiding area due to underwater exploitation.

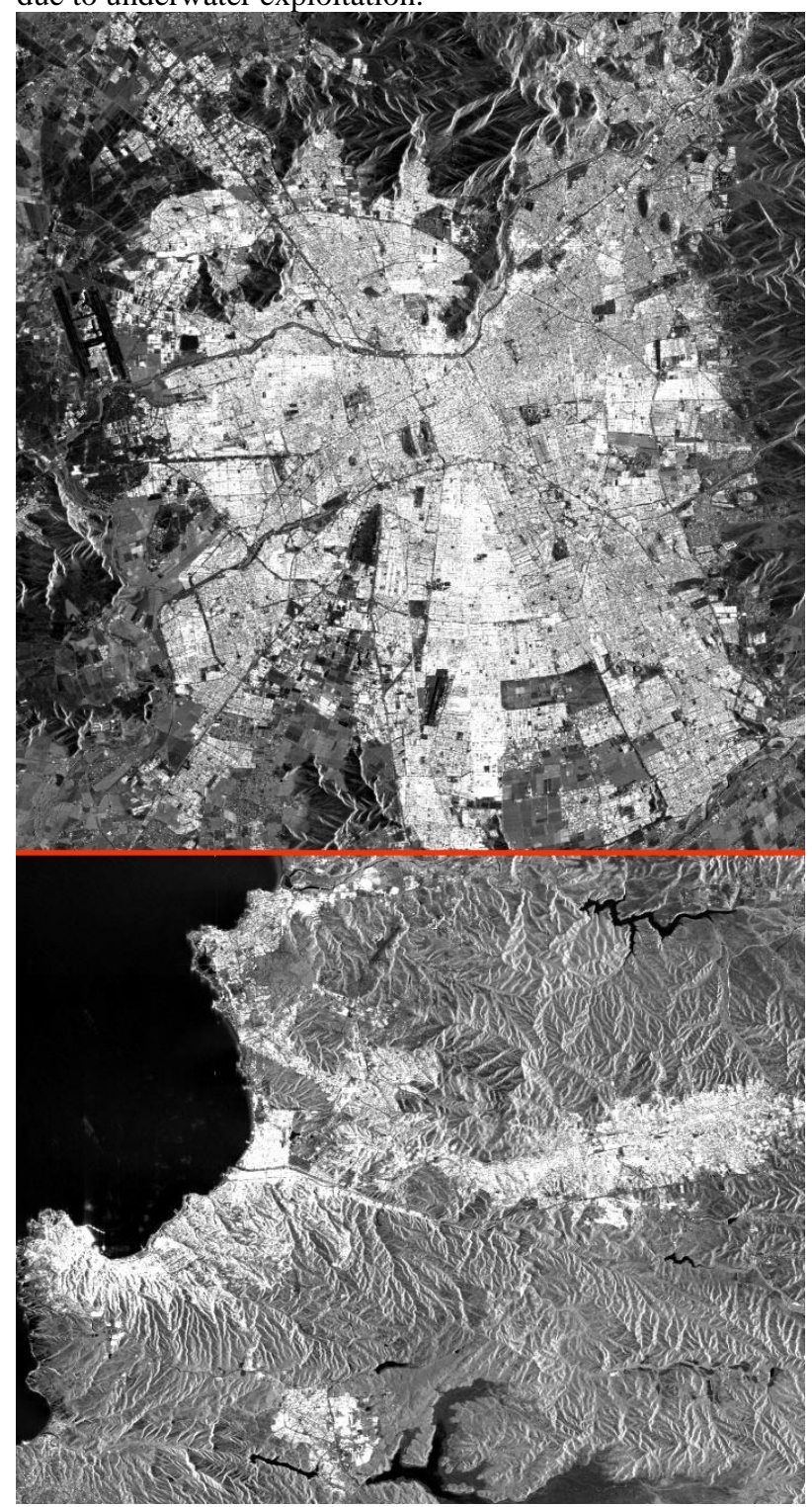

Figure 1. (up) mean amplitude image of Santiago (bottom) mean amplitude image of Valparaíso.

The second example is located in the south-east part of the city (Figure 3B). In this case we observe an area that is free of building and seems under construction. In this case, the maximum observed velocity is $25 \mathrm{~mm} / \mathrm{yr}$. Again, this movement is interpreted as subsidence due to settlements.

Both cases are examples of movements that are not critical and that probably have no effects on the population and on the surrounding structures. At least they are not noticed yet. However, the detection of these type of movements can reveal, in some cases, illegal activities like underwater exploitation, tunnelling or construction works. Its knowledge can also be useful for local authorities to have a picture of the active areas in the city prior to start construction works of critical infrastructures like subway lines. Therefore, the possibility of systematically apply this type of approaches on crowded areas like Valparaíso or Santiago provides a continuous set of measurements that is valuable information for both urban planning and geohazard risk prevention. 


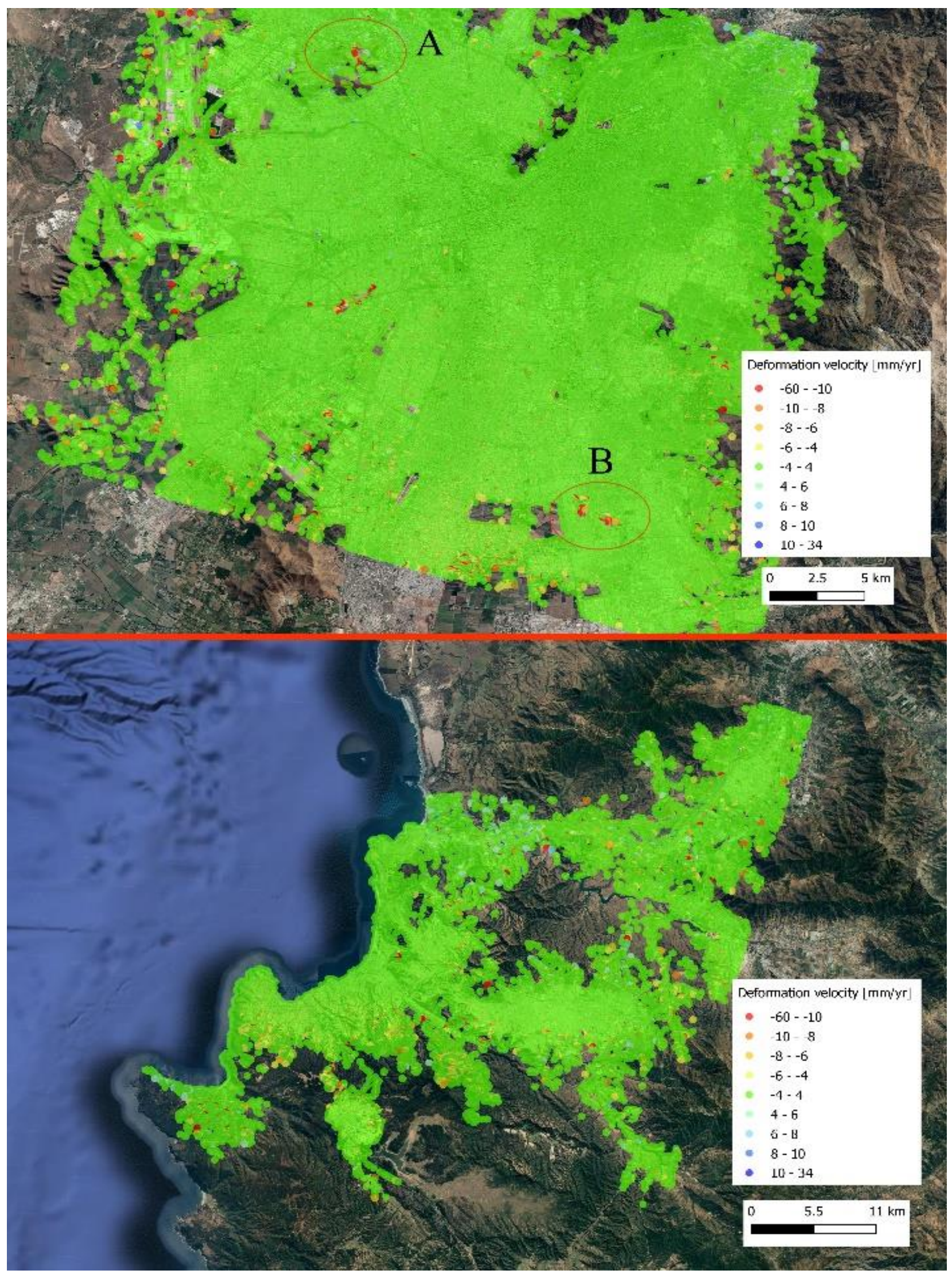

Figure 2. (up) Deformation velocity mape of Santiago (bottom) Deformation velocity mape of Valparaíso. 


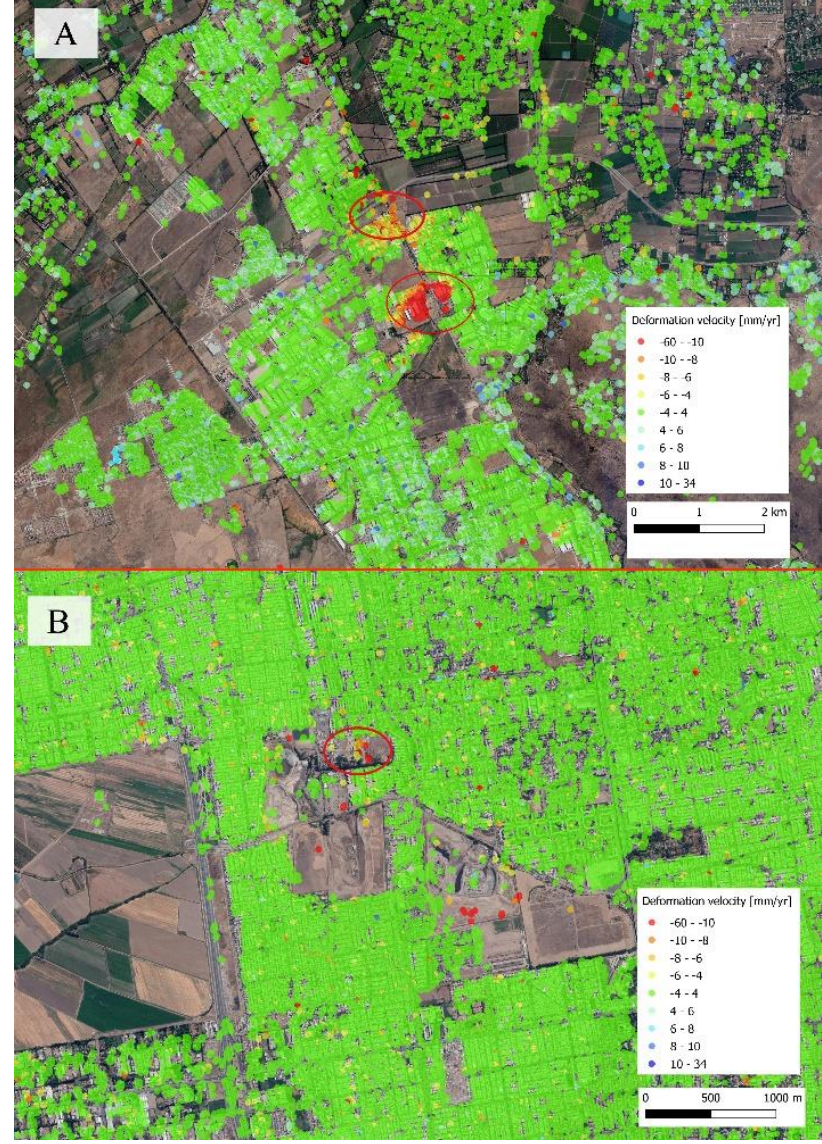

Figure 3. (up) Deformation velocity map of Santiago (bottom) Deformation velocity map of Valparaíso.

\section{SENTINEL-1 A-DINSAR FOR FAST ASSESMENT OF GEOHAZARD ACTIVITY IN NATURAL ENVIRONMENTS}

In this section we show an example of application of a fast and unsupervised approach to map and monitor active areas in remote and natural environments. It is applied in along the Copiapó river basin. The used approach provides a fast and easy solution to screen wide areas and to map and check the evolution of relatively fast and local movements. The idea besides is to try to exploit the high coherence from the short temporal baseline interferograms provided by Sentinel-1.

The input data consist of a set of $\mathrm{N}$ images and the corresponding $\mathrm{N}-1$ interferograms calculated by using consecutive images. The approach has three main steps:

(i) phase unwrapping of the $\mathrm{N}-1$ interferograms removing only those points with very low coherence.

(ii) direct integration of the phases: the accumulated phase on time is estimated for each point as follows:

$$
\left\{\begin{array}{c}
\varphi_{i}=\varphi_{i-1}+\Delta \varphi_{i(i-1)} \quad i=1 \div N \\
\varphi_{0}=0
\end{array}\right.
$$

Where $\varphi_{i}$ is the accumulated phase at the acquisition time $i$, and $\Delta \varphi_{i(i-1)}$ is the interferometric phase between the images $i$ and $i$ 1 . (iii) Atmospheric phase filtering: in this step is used the Butterworth filter to remove the atmospheric contribution to the phases $\varphi_{i}$ (spatial low phase variation).

(iv) Phase to displacement transformation and geocoding: the accumulated phase of each measured point is transformed to displacement as follows:

$$
\operatorname{Defo}(i)=\varphi_{i} * \frac{\lambda}{4 * \pi}
$$

Where $\lambda$ is the wavelength and then the corresponding ground coordinates are found.

This approach is not supervised and do not provide quality estimators. However, it provides quantitative measurements that can be helpful to decide whether or not is needed to apply more reliable approaches.

\subsection{Dataset and main results}

Figure 4 shows the results obtained in the Copiapó basin. It shows the accumulated deformation along the period ranging from October 2014 and March 2019. The number of processed images is 81 . The total number of points is 2374445 . At a first glance it is easy to observe the high coverage of the obtained results. The accumulated deformation map has a standard deviation $(\sigma)$ of 5 $\mathrm{mm}$. We have used two times the $\sigma$ value as a stability threshold

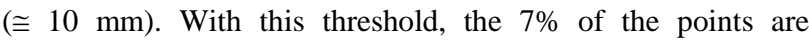
considered moving points.

A, B, C, D in Figure 4 point different areas along the Copiapó River. These areas have soft cyan colour that represent displacement towards the satellite. This, in case of vertical displacements, is interpreted as uplift. Figure 5 shows the average displacement time series for each one of these areas. It can be observed a good correlation between them. The average correlation between the time series is 0.88 . The time series show a clear trend of displacements towards the satellite along the measured period. This trend could be explained by an uplift due to recuperation of the Copiapó basin. Moreover, the time series show periods of trend change that could be explained by seasonal variation of the water level in the area. This preliminary interpretation should be confirmed by further analysis.

Figure 6 shows another interesting area affected by displacements. In this case, the movements are related to mining activity. Most of the detected displacements in this area are related to slope instabilities. In this particular case we can see movements towards (blue) and far (red) from the satellite. The explanation to this is that the measured movements are landslides and the sign of the deformation is explained by the landslide aspect with respect the satellite. The maximum accumulated displacement in the open pit areas is $184 \mathrm{~mm}$. An interesting area is the tailing dam (delimited by an ellipse). The figure shows the average displacement time series on this area. The accumulated displacement raises in average $65 \mathrm{~mm}$. However, it must be underlined that these numbers can be underestimated due to phase unwrapping errors. This can be clearly seen in the time series shown in Figures 6. We see a more or less regular trend towards the satellite that seems to has not continuity in a period without images (bounded by a rectangle). In this case the trend interruption is probably due to phase unwrapping errors. It is worth noting that despite these potential errors, the target of the analysis is fulfilled. It provides enough information to decide whether is needed or not a more in depth analysis to properly analyse the detected active area. 


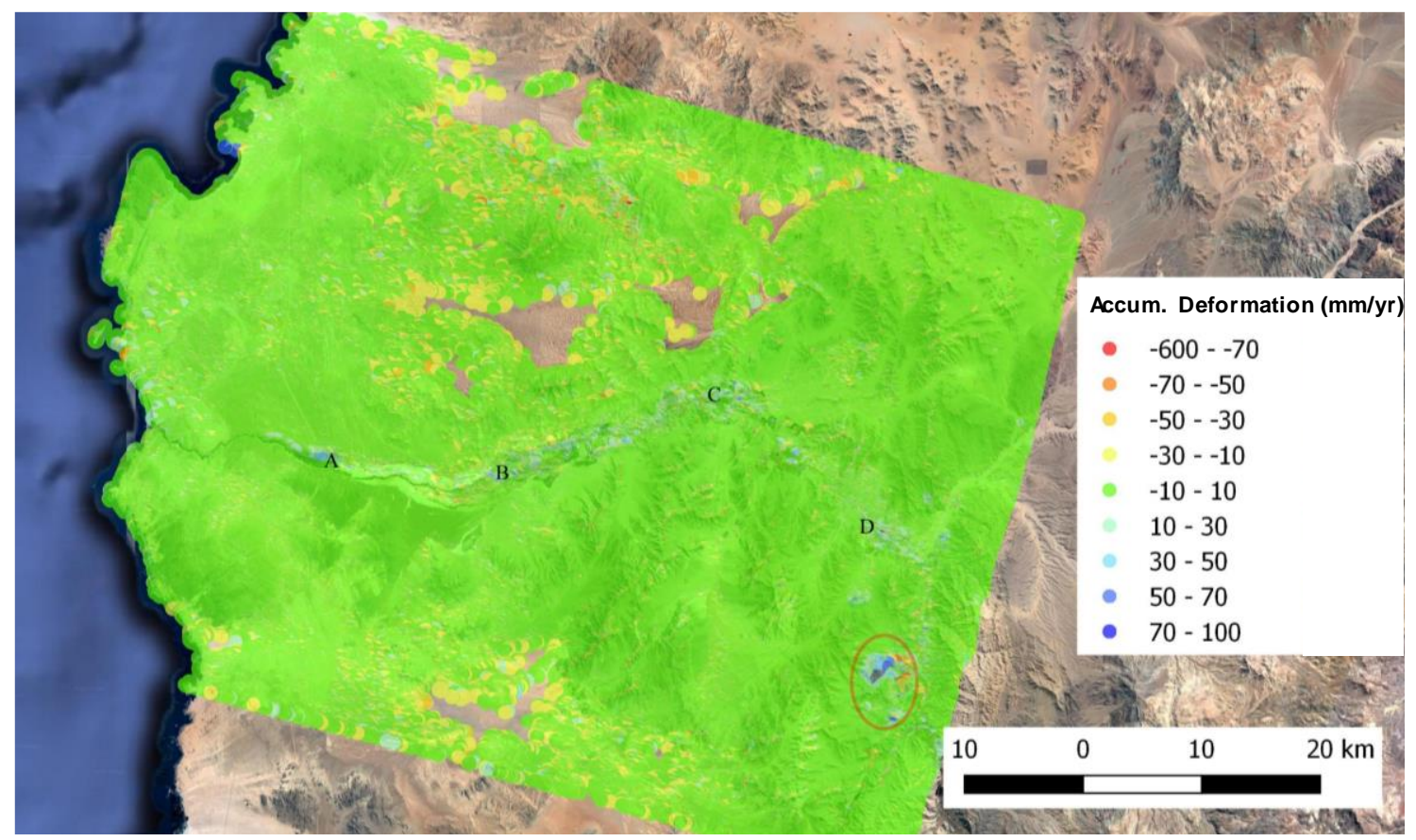

Figure 4. Displacement map of the Copiapó Basin superimposed to an optical image of Google Earth.

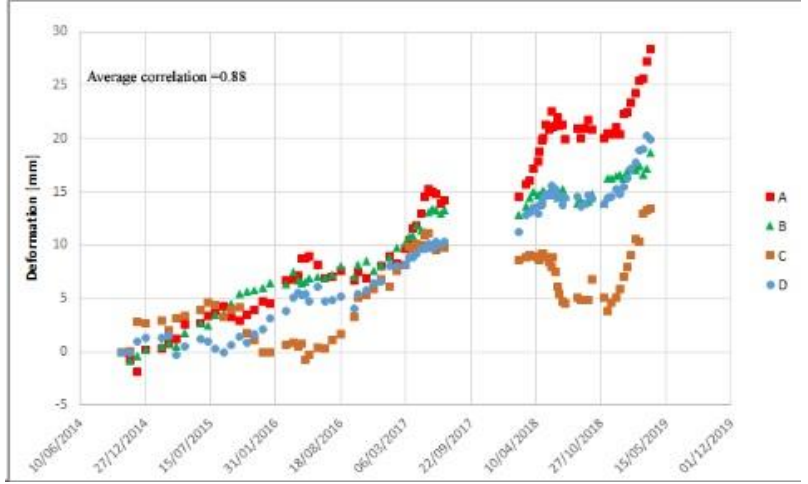

Figure 5. Displacement time series at different areas of the Copiapó river. A, B, C and D of Figure 4. The average correlation between them is 0.88 .

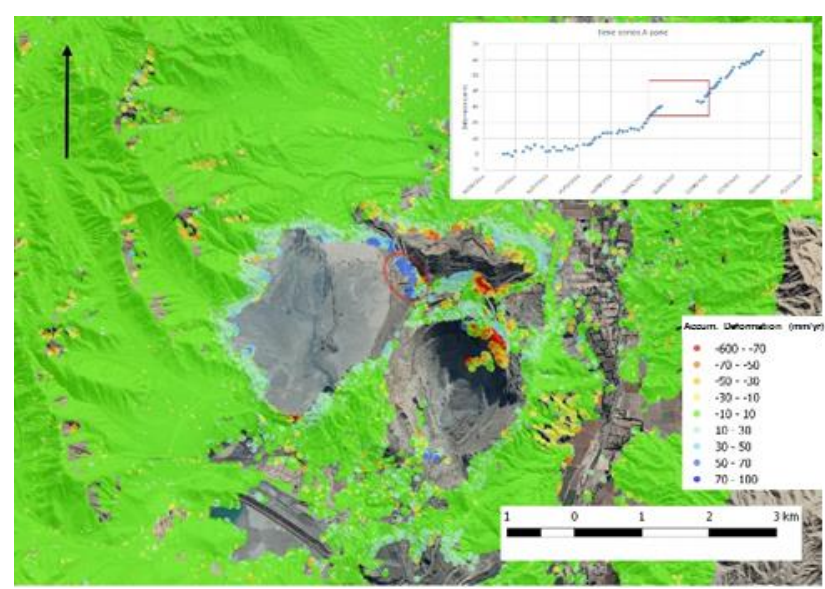

Figure 6. Zoom of the area marked by an ellipse in figure 4.

\section{DISCUSSION AND CONCLUSION}

In this work are shown three examples of application of Sentinel1 imagery to map active geohazards. These examples, which have been developed by Sernageomin in collaboration with CTTC, demonstrate the potentialities of these type of data to be used operationally for geohazard risk management.

The first two examples deal with mapping slow displacements in urban areas. The interferometric based tool to map the displacements is the displacement velocity map. It is calculated in Santiago and Valparaíso for the period 2017-2018. A total of 1.6 million and 525 thousand of measurements have been obtained for Santiago and Valparaíso respectively. The overall estimated precision is $2 \mathrm{~mm} / \mathrm{yr}$. The results illustrate the nice performances that Sentinel-1 data provides for this type of application. The results have been used to map several displacements in both cities: two of them are shown in this work. The application of this approach in a systematic way can provide key information for both urban planning but also to map new active areas for risk management purposes.

The third example is the result of applying a fast and unsupervised approach to map displacements in non-urban areas. The approach aims to fully exploit the high coherence of the Sentinel-1 12-day interferograms. The main output of the approach is, for each point, the displacement time series. 2.3 millions of points have been measured in the Copiapó river basin. The results have provided information about some deformation phenomena in the region. Two different examples have been shown: the uplift affecting the Copiapó river basin and different slope instabilities in an open pit mine. Despite in some cases the approach does not allow to infer concluding remarks, it is quite useful to understand the nature of the displacement and to drive more focused analysis. 


\section{ACKNOWLEDGEMENTS}

The CTTC contribution has been partially funded by the Ministry of education and professional training of the Spanish government through the program abroad stages for young researchers José Castillejo (Ref: CAS19/00190) and by the European Commission, Directorate-General Humanitarian Aid and Civil Protection (ECHO), through the U-Geohaz project, "Geohazard impact assessment for urban areas" (UCPM-2017-PP-AG: UCPM-783169)

\section{REFERENCES}

Barra, A., Monserrat, O., Mazzanti, P., Esposito, C., Crosetto, M., \& Scarascia Mugnozza, G. (2016). First insights on the potential of Sentinel-1 for landslides detection. Geomatics, Natural Hazards and Risk, 7(6), 1874-1883..

Barra, A., Solari, L., Béjar-Pizarro, M., Monserrat, O., Bianchini, S., Herrera, G., ... \& Ligüerzana, S. (2017). A methodology to detect and update active deformation areas based on sentinel-1 SAR images. Remote Sensing, 9(10), 1002.

Béjar-Pizarro, M., Notti, D., Mateos, R. M., Ezquerro, P., Centolanza, G., Herrera, G., ... \& Fernández, J. (2017). Mapping vulnerable urban areas affected by slow-moving landslides using Sentinel-1 InSAR data. Remote Sensing, 9(9), 876.

Béjar-Pizarro, M., Álvarez Gómez, J., Staller, A., Luna, M., Pérez-López, R., Monserrat, O., ... \& Mateos, R. (2018). InSARbased mapping to support decision-making after an earthquake. Remote Sensing, 10(6), 899.

Berardino, P., Fornaro, G., Lanari, R., Sansosti, E., 2002. A new algorithm for surface deformation monitoring based on small baseline differential SAR interferograms. IEEE TGARS, 40(11), 2375-2383.

Biescas, E., Crosetto, M., Agudo, M., Monserrat, O., Crippa, B., 2007. Two radar interferometric approaches to monitor slow and fast land deformation. J. Surv. Eng. 133 (2), 66-71.

Bovenga, F., Wasowski, J., Nitti, D.O., Nutricato, R., Chiaradia, M.T., 2012. Using COSMO/SkyMed X-band and ENVISAT Cband SAR interferometry for landslides analysis. Remote Sens. Environ. 119, 272-285.

Bredal, M., Dehls, J., Larsen, Y., Marinkovic, P., Lauknes, T. R., Stødle, D., \& Moldestad, D. A. (2019, ). The Norwegian National Ground Motion Service (InSAR. no): Service Evolution. In $A G U$ Fall Meeting 2019. AGU.

Catani, F., Casagli, N., Ermini, L., Righini, G., \& Menduni, G. (2005). Landslide hazard and risk mapping at catchment scale in the Arno River basin. Landslides, 2(4), 329-342.

Costantini, M., Malvarosa, F., Minati, F., Pietranera, L., Milillo, G., 2002. A three-dimensional phase unwrapping algorithm for processing of multitemporal SAR interferometric measurements. Proceedings of IGARSS 2002, Toronto.

European Ground Motion Service (EU-GMS) white paper 2017, (EGS_EU_GMS_white_paper)

Ferretti, A., Prati, C., Rocca, F., 2001. Permanent scatterers in SAR interferometry. IEEE TGARS, 39(1), 8-20.
Herrera, G., Davalillo, J.C., Mulas, J., Cooksley, G., Monserrat, O., Pancioli, V., 2009. Mapping and monitoring geomorphological processes in mountainous areas using PSI data: central Pyrenees case study. Nat. Hazards and Earth Syst. Sci. 9 (5), 1587-1598.

González, P. J., Bagnardi, M., Hooper, A. J., Larsen, Y., Marinkovic, P., Samsonov, S. V., \& Wright, T. J., 2015. The 2014-2015 eruption of Fogo volcano: Geodetic modeling of Sentinel-1 TOPS interferometry. Geophysical research letters, 42(21), 9239-9246.

Kalia, A. C., Frei, M., \& Lege, T. (2017). A Copernicus downstream-service for the nationwide monitoring of surface displacements in Germany. Remote Sensing of Environment, 202, 234-249.

Kimura, H., \& Yamaguchi, Y. (2000). Detection of landslide areas using satellite radar interferometry. Photogrammetric Engineering and Remote Sensing, 66(3), 337-344.

Lanari, R., Mora, O., Manunta, M., Mallorquí, J.J., Berardino, P., Sansosti, E., 2004. A small-baseline approach for investigating deformations on full-resolution differential SAR interferograms. IEEE TGRS 42 (7), 1377-1386.

Lombardini, F., 2005. Differential tomography: A new framework for SAR interferometry. IEEE TGARS, 43(1), 37-44.

Monserrat, O., Crosetto, M., Cuevas, M., Crippa, B., 2011. The thermal expansion component of Persistent Scatterer Interferometry observations. IEEE Geosci. Remote Sens. Letters, $8,864-868$

Osmanoğlu, B., Dixon, T. H., Wdowinski, S., Cabral-Cano, E., \& Jiang, Y., 2011. Mexico City subsidence observed with persistent scatterer InSAR. International Journal of Applied Earth Observation and Geoinformation, 13(1), 1-12.

Raucoules, D., Bourgine, B., De Michele, M., Le Cozannet, G., Closset, L., Bremmer, C., Veldkamp, H, Tragheim, D., Bateson, L., Crosetto, M., Agudo, M., Engdahl, M., 2009. Validation and intercomparison of Persistent Scatterers Interferometry: PSIC4 project results. J. of Applied Geophysics, 68(3), 335-347.

Raspini, F., Bianchini, S., Ciampalini, A., Del Soldato, M., Solari, L., Novali, F., ... \& Casagli, N., 2018. Continuous, semiautomatic monitoring of ground deformation using Sentinel-1 satellites. Scientific reports, 8(1), 7253.

Tomás, R., Cano, M., García-Barba, J., Vicente, F., Herrera, G., Lopez-Sanchez, J.M., Mallorquí, J.J., 2013. Monitoring an earthfill dam using differential SAR interferometry: La Pedrera dam, Alicante, Spain. Engineering Geology, 157, 21-32.

Tomás, R., Pagán, J. I., Navarro, J. A., Cano, M., Pastor, J. L., Riquelme, A., ... \& Lopez-Sanchez, J. M. (2019). Semi-automatic identification and pre-screening of geological-geotechnical deformational processes using persistent scatterer interferometry datasets. Remote Sensing, 11(14), 1675.

Torres, R., Snoeij, P., Geudtner, D., Bibby, D., Davidson, M., Attema, E., Potin, P., Rommen, B., Floury, N., Brown, M., Navas Travera, I., Deghaye, P., Duesmann, B., Rosich, B., Miranda, N., Bruno, C., L'Abbate, M., Croci, R., Pietropaolo, A., Huchlerc, M., Rostan, F., 2012. GMES Sentinel-1 mission. Remote Sensing of Environment, 120, 9-24. 